\title{
A contribuição do serviço social na garantia da permanência dos estudantes na educação básica: um estudo a partir das escolas públicas estaduais do município de Rolândia/PR
}

The contribution of Social Work in the permanence of students in basic education: a study from the public schools in the City of Rolândia/PR

\author{
Jaqueline Natália de Almeida* \\ Claudia Neves da Silva**
}

\begin{abstract}
Resumo:
A escola é um espaço social caracterizado pela presença de situações provocadas pelas condições materiais de existência dos estudantes, as quais se reproduzem e se conflituam no cotidiano acadêmico. Neste artigo, propomo-nos a investigar como o Serviço Social poderá contribuir para a permanência dos estudantes na escola. Para a concretização da pesquisa, foram entrevistados três diretores e uma diretora auxiliar de todas as escolas públicas estaduais do Município de Rolândia/PR. Para a superação da evasão escolar, tanto em municípios de pequeno quanto médio ou grande porte, a educação não pode ser efetivada isoladamente das demais políticas sociais, ao contrário, devem ser implementadas de forma articulada com a saúde, a habitação, a assistência social. E o Serviço Social, por meio de sua atuação profissional, poderá contribuir para a efetivação do direito à educação.
\end{abstract}

Palavras-chave: Serviço social; Educação; Evasão escolar; Permanência

\begin{abstract}
:
The school is a social space characterized by the presence of situations caused by the material conditions of existence of the students, which reproduce daily academic. In this article, we propose to investigate how the Social Work can contribute to students' stay in school. To achieve the research were interviewed three directors and a director supporting all public schools in the municipality of Rolândia / PR. To overcome truancy, whether in municipalities of small, medium or large, education can not be conducted in isolation from other social policies, rather it should be implemented in coordination with the health, housing, social assistance. And Social Work, through their professional practice, can contribute to the realization of the right to education.
\end{abstract}

Keywords: Social work; Education; High school dropout.

\footnotetext{
* Assistente Social, formada pela Universidade Estadual de Londrina em 2012. Atualmente é aluna do curso de PósGraduação em Gestão de Pessoas, da Faculdade Paranaense (FACCAR). E-mail: jaquelinenatalia17@hotmail.com

** Professora Adjunta do Departamento de Serviço Social da Universidade Estadual de Londrina. Doutora em História Social pela Universidade Estadual Paulista. Coordenadora do Projeto de Extensão "Serviço Social na área Escolar". E-mail: claudianeves@sercomtel.com.br ; claudianevess@uel.br
} 


\section{Introdução}

A escola é uma instituição com significativa influência na vida dos indivíduos e da comunidade, haja vista que as crianças iniciam sua vida acadêmica desde tenra idade, e quando entram na adolescência transformam-na no local para onde levam suas expectativas, dificuldades, angústias, anseios e esperanças. Com efeito, podemos afirmar que a escola é um espaço social caracterizado pela presença de situações provocadas pelas condições materiais de existência dos estudantes e seus familiares, as quais se reproduzem e se conflituam no cotidiano acadêmico.

Nesse sentido, a inserção do Assistente Social em uma instituição escolar deve conciliar o seu saber com as experiências que lhe são trazidas pelos estudantes e com os conhecimentos de professores, pedagogos, zeladores e demais funcionários, avaliando e revendo a sua prática profissional (GONÇALVES, 2009). Experiências e conhecimentos que promovem uma convivência entre os diversos e diferentes sujeitos, que por lá transitam, provocam situações que podem ter consequências diversas ao que propõe a política de educação, como, por exemplo, a repetência, a evasão e o fracasso escolar.

A partir dessa constatação, alguns questionamentos surgiram: quais as possibilidades de atuação do/da assistente social para garantir que o princípio referente à igualdade e condição da permanência dos estudantes promulgados na Constituição Federal de 1988 e a Lei de Diretrizes e Base da Educação Nacional (LDBEN) seja efetivado? O/A assistente social, com base na Lei 8662/93 e o Código de Ética em vigor, tem condições de garantir esse direito?

Neste artigo, propomo-nos avaliar como o Serviço Social, por meio de sua atuação profissional, poderá contribuir para a permanência dos estudantes na escola e, assim, tenham acesso a uma educação escolarizada que contemple a inclusão social de crianças, adolescentes e jovens. Cabe destacar que não temos por intenção discorrer sobre concepções de educação ou sobre a política de educação do Brasil, mas apenas colaborar com o debate acerca das possibilidades de atuação do Serviço Social em instituições escolares, lócus privilegiado para o acesso de crianças e adolescentes aos serviços e bens da comunidade. 
Como afirma Santiago (2012, p. 4) “[...] a escola, indubitavelmente, acolhe a esperança de um mundo melhor e torna-se uma instituição importante e indispensável na luta por uma sociedade mais equânime, com menos sofrimento e menos riscos ecológicos".

Para a concretização deste estudo, foram entrevistados três diretores e uma diretora auxiliar de todas as escolas públicas estaduais do município de Rolândia, que atendem os anos finais do ensino fundamental $\left(6^{\circ}\right.$ ao $9^{\circ}$ ano), totalizando quatro escolas: duas localizadas na região central e duas na periferia.

O município de Rolândia localiza-se na região norte do Estado do Paraná, e de acordo com o censo de 2010 contabiliza 57.862 habitantes (IBGE, 2014). Sua base econômica concentra-se na agricultura - soja, milho, trigo, cana de açúcar e laranja, mas a pecuária também tem significativo destaque. Como os setores industrial e de comércio são insipientes, os moradores voltam-se para atividades ligadas ao setor primário, que não exige qualificação especializada.

Apesar de termos realizado a pesquisa em um município de pequeno porte, acreditamos que a realidade não se diferencia nos demais municípios, seja ele de pequeno, médio ou grande porte, tendo em vista que os problemas sociais que se manifestam no interior das unidades escolares são consequências das desigualdades sociais, política e econômica da sociedade brasileira. Portanto, situações presentes no cotidiano das escolas públicas espalhadas pelo Brasil.

\section{A política de educação e a educação que almejamos}

Para entendermos a política de educação no Brasil, devemos partir da Constituição promulgada em 1988, considerada um avanço no que se refere às políticas sociais. No Art. 205 está determinado que:

A educação, direito de todos e dever do Estado e da família, será promovida e incentivada com a colaboração da sociedade, visando ao pleno desenvolvimento da pessoa, seu preparo para o exercício da cidadania e sua qualificação para o trabalho (BRASIL, 1988). 
Em seu Artigo 206 aponta que "O ensino será ministrado com base nos seguintes princípios: I - igualdade de condições para o acesso e permanência na escola [...]" (BRASIL, 1988).

Porém, conforme o Censo Demográfico de 2010 (IBGE, 2010), a taxa de abandono no ensino fundamental dos anos finais (6으 ao 9o ano) foi de 4.7\%, cuja faixa etária esta entre os 11 e 15 anos. Isto significa que esta população ao não permanecer nos bancos escolares deixa de usufruir de uma educação que possibilita o acesso ao saber científico, à história de sua comunidade e à interlocução com outros saberes e experiências.

Diante desses números, surgem indagações cujas respostas extrapolam os limites deste artigo: quais os motivos para a não permanência na escola? Quais as garantias para a permanência dos estudantes em sala de aula? E abordando um município em particular - Rolândia: como o poder público e a escola têm trabalhado a questão da evasão escolar?

Para respondermos a estas indagações, iniciamos com a Lei de Diretrizes e Base da Educação Nacional, que em seu Artigo 2ㅇ destaca que:

A educação, dever da família e do Estado, inspirada nos princípios de liberdade e nos ideais de solidariedade humana, tem por finalidade o pleno desenvolvimento do educando, seu preparo para o exercício da cidadania e sua qualificação para o trabalho (BRASIL, 1996).

Todavia, precisamos ir além dessa definição oficial, ou seja, entender sua importância e necessidade, já que a educação apresenta-se como um campo em que grupos sociais buscam legitimar e reproduzir suas ideias, tendo assim uma "função social importante na dinâmica da reprodução social [...] marcada pelas contradições, pelos projetos e pelas lutas societárias e não se esgota nas instituições educacionais, embora tenha nelas um espaço privilegiado de objetivação" (CONSELHO FEDERAL DE SERVIÇO SOCIAL, 2011, p. 16).

A educação, como política e estratégia defendida por todos os setores da sociedade, é um campo em que disputam grupos e classes sociais cujos interesses são de natureza diversa e antagônica, pois de um lado há os que querem impor e manter o consenso e a harmonia social por meio de uma educação passiva, que reproduz valores e ideias dos grupos dominantes, e por outro há os que buscam a formação de saberes e práticas que provoquem rupturas na produção e reprodução das condições materiais e culturais de 
existência, estabelecendo, desta forma, relações que se pautam na igualdade de condições entre os "desiguais".

Conforme Frigotto (2010, p. 27), “Esta disputa dá-se na perspectiva de articular as concepções, a organização dos processos e dos conteúdos educativos na escola e, mais amplamente, nas diferentes esferas da vida social, aos interesses de classe".

Como se pode constatar, a educação é um processo de socialização historicamente produzida e reproduzida conforme os interesses e necessidades de grupos ou classe social, uma ação "[...] concebida como uma prática social, uma atividade humana e histórica que se define no conjunto das relações sociais, no embate dos grupos ou classes sociais, sendo ela mesma forma específica de relação social" (FRIGOTTO, 2010, p. 33).

Seguindo essa linha de raciocínio, a educação esta à mercê da reprodução de uma estrutura que coisifica o indivíduo, impossibilitando-o de desvelar e questionar a realidade social, cultural, política e econômica, desenvolver-se autonomamente e emancipar-se para a construção de uma nova realidade em que haja igualdade de acesso aos bens e serviços da comunidade e respeito à diversidade. Para garantir que a educação contribua de forma decisiva para a construção de uma nova sociedade, as instituições encarregadas de transmitir e retransmitir conhecimentos e experiências devem se voltar para as necessidades de todos, indistintamente.

De acordo com Frigotto (2010, p. 34), existem direitos que são inatos ao indivíduo, os quais quando negados agridem a condição humana:

A qualificação humana diz respeito ao desenvolvimento de condições físicas, mentais, afetivas, estéticas e lúdicas do ser humano (condições omnilaterais) capazes de ampliar a capacidade de trabalho na produção dos valores de uso em geral como condição de satisfação das múltiplas necessidades do ser humano no seu devenir histórico.

A educação formal escolarizada traz a possibilidade e a garantia de construir uma educação emancipadora, que se preocupa com a troca e a transmissão de valores e conhecimentos populares - geralmente classificados por aqueles que detêm o poder político e econômico como saberes supersticiosos, sem fundamentação e comprovação científica -, contribuindo para a formação de organizações coletivas que levem à 
construção da autonomia e desenvolvimento intelectual de homens e mulheres, respeitando e valorizando seus saberes e experiências.

Educação emancipadora que garanta e fortaleça a capacidade de o indivíduo expor seus pensamentos, sua compreensão de sociedade, de cultura, de política, realizar atividades formativas que questionam a banalização e naturalização da violência e a discriminação social, étnica, de gênero: “É preciso superar a perda da capacidade humana de realizar experiências formativas e a condição de objeto a que o homem se reduziu num mundo instrumentalizado pelo capital [...]" (QUINTAL, 2010, p. 12).

Seguindo essa linha de raciocínio, a permanência dos adolescentes e jovens nos bancos escolares, tendo acesso a descobertas científicas, filosóficas e sociológicas, possibilitará que entendam a sociedade em que vivem e desenvolvam pensamentos e ações criativas que os levem a questionar e intervir para superar situações de exclusão, discriminação e violência de gênero e homofóbica.

\section{Educação emancipadora e na (não) permanência dos estudantes nos bancos escolares}

Conforme Haddad, Franco e Silva (2011, p. 276) "a escola e a sociedade estão em constante movimento, oriundos das contradições que possibilitam as mudanças". Contradições porque a escola é o espaço onde crianças, adolescentes e jovens poderiam compartilhar experiências e vislumbrar condições para questionar a realidade social, política e econômica, mas se deparam com situações como a falta de professores, salas de aula com número elevado de estudantes, docentes mal remunerados e mal preparados para lidarem com estudantes provenientes de realidades distintas da sua: valores morais, religiosos, familiares; condição socioeconômica que levam os educandos a terem que dividir seu tempo entre casa, escola, trabalho. Sem falar no apelo constante que recebem todos os dias da mídia, qual seja, consumir incessantemente para satisfazer desejos e prazeres.

Diante desta realidade, a construção e efetivação de uma educação emancipadora fica comprometida, porque dificulta o processo ensino-aprendizagem, provoca a desmotivação e o desinteresse para estudar e participar das aulas e atividades escolares leva à repetência, e por fim a não permanência na sala de aula, com o consequente abandono da escola, ou seja, a evasão. 
Para melhor compreendermos a realidade escolar do município de Rolândia, apresentaremos o perfil daquelas que fizeram parte do universo de nossa pesquisa. $\mathrm{Na}$ verdade, são escolas que não se diferenciam das demais unidades de ensino espalhadas pelos 399 municípios do Estado do Paraná.

São quatro escolas que atendem a um número significativo de alunos:

Quadro 1 - Perfil das escolas públicas estaduais de Rolândia

\begin{tabular}{|l|l|l|l|l|}
\hline Escola & No de estudantes & $\begin{array}{l}\text { № de } \\
\text { professores }\end{array}$ & $\begin{array}{l}\text { № de } \\
\text { funcionários }\end{array}$ & № de turmas \\
\hline W & Não forneceu & 81 & 31 & 28 \\
\hline X & 1.500 & 95 & 24 & 22 \\
\hline Y & 830 & 71 & 19 & 27 \\
\hline Z & Não forneceu & 81 & 22 & 25 \\
\hline
\end{tabular}

Fonte: Questionário aplicado junto aos diretores das escolas públicas de Rolândia em 2012.

Quanto aos diretores, são docentes das escolas há mais de 15 anos (que fizeram parte do universo da pesquisa), tempo suficiente para conhecer a realidade social, familiar, cultural e econômica de seus estudantes, fator importante para entender e enfrentar os problemas de ordem pessoal, familiar, social e psicológica que alguns trazem para a sala de aula:

Quadro 2 - Perfil dos gestores das escolas

\begin{tabular}{|l|l|l|}
\hline Gestor/a & $\begin{array}{l}\text { Tempo de docente nesta } \\
\text { escola }\end{array}$ & Tempo de gestor nesta escola \\
\hline A & 16 & 06 meses \\
\hline B & 15 & 06 meses \\
\hline C & 18 & 06 meses \\
\hline D & 21 & 36 meses \\
\hline
\end{tabular}

Fonte: Questionário aplicado junto aos diretores das escolas de Rolândia em 2012.

Para garantir uma escola voltada para as demandas do aluno, professores, família e comunidade, deparam-se com um desafio, qual seja, torná-la um instrumento que possibilite a interação social, não limitando o processo educativo ao seu interior. E um dos primeiros desafios é entender e combater a evasão escolar.

De acordo com Ruaro (2012) ${ }^{1}$, a evasão escolar é um problema que ocorre como efeito da situação socioeconômica e cultural dos educandos, os quais se veem obrigados a abandonar os estudos para ajudar no sustento e manutenção de suas famílias. Na pesquisa

\footnotetext{
${ }^{1}$ No artigo não consta o ano em que foi publicado. A data refere-se ao ano em que o mesmo foi acessado.
} 
realizada, verificamos que tanto nas escolas localizadas na região central quanto na periferia a evasão escolar permanece:

Quadro 3 - Alunos evadidos em 2011

\begin{tabular}{|l|l|l|l|l|}
\hline Escola & Localização & Ingressantes/2011 & Evadidos/2011 & Percentual/2011 \\
\hline X & Periferia & 741 & 67 & $9.0 \%$ \\
\hline W & Centro & 920 & 26 & $2.8 \%$ \\
\hline Y & Periferia & 756 & 26 & $3.4 \%$ \\
\hline Z & Centro & 755 & 68 & $9.0 \%$ \\
\hline
\end{tabular}

Fonte: Questionário aplicado junto aos diretores das escolas de Rolândia em 2012

O diretor $\mathrm{A}$ da escola $\mathrm{X}$ reconhece o problema da evasão ao afirmar que "uma grande quantidade de alunos começa e poucos terminam", não obstante destaca que o número de evadidos diminuiu ao longo dos anos "antes nós tínhamos turmas com 25 alunos começando e 5 se formando".

Conforme a diretora $B$ da escola $Z$, a maioria dos estudantes reside na periferia "[...] 90\% são da periferia [...] são todos alunos da periferia que não têm condições financeiras, então nossos alunos são paupérrimos".

Nos grupos sociais dos setores populares, a escola é vista como garantia de um futuro melhor, levando muitas famílias a promoverem um investimento - financeiro e humano no estudo de seus filhos. Contudo, com a necessidade dos adolescentes terem que arrumar "bicos" para ajudar no sustento familiar, começa a surgir dificuldades para frequentar a escola regularmente, advindo, assim, o desânimo e a falta de motivação para continuação e manutenção dos estudos (GOMES apud PEREZ, 2009).

As condições para que os discentes permaneçam na escola ultrapassam os seus muros, já que estão relacionadas ao contexto social, cultural, econômico e político. Portanto, para entender, e combater a evasão escolar, é necessário termos clareza que são múltiplas e variadas as situações e obstáculos:

[...] Muitas vezes por terem que trabalhar para ajudar no orçamento do lar, a incompatibilidade no horário para o estudo, o desgaste prematuro no trabalho, não sobrando tempo e ânimo para estudar, a distância da escola de suas casas, ou mesmo a falta de moradia fixa, com constantes mudanças de endereços, uma escola não atrativa, autoritária, professores despreparados, ausência de motivação, sem propostas pedagógicas, aluno indisciplinado, com problema de saúde, gravidez precoce, uso de violência doméstica, negligência dos pais ou responsáveis, uso indevido de drogas, desestrutura familiar, baixo poder aquisitivo para aquisição de materiais escolares, exigidos pelas escolas, violência 
e outras causas oriundas do sistema capitalista e educacional do país (PIANA; CANÔAS, 2007, p. 215).

Assim, ao buscar as causas para o desinteresse na educação escolarizada, levando muitos a ficarem retidos na série e outros a evadirem da escola, devemos levar em conta os fatores externos, como "[...] precárias condições econômicas e sociais da população, formação histórica colonizada, poderes públicos irresponsáveis ou atrelados aos interesses de uma elite predatória, etc." (CORTELLA apud RUARO, 2012, p. 5).

Contudo, há outros fatores que colaboram para a não frequência às aulas, como os fatores internos - o não cumprimento pelo Estado da efetivação de uma educação que atenda aos anseios e às necessidades de uma grande parcela da população que se encontra excluída do acesso aos bens e serviços da comunidade: "a deficiência da gestão dos poucos recursos destinados às instituições, formação ineficiente dos professores, formação continuada quase inexistente" (RUARO, 2012, p. 5), não sendo possível, desta forma, garantir a frequência do estudante à escola.

Verificamos essa situação em outros municípios brasileiros; a título de exemplo, citamos uma reportagem que informa que o Ministério da Educação criou um grupo de trabalho com a finalidade de identificar as causas da evasão escolar: "O ministério da Educação (MEC) criou um grupo de trabalho com objetivo de elaborar um manual para o combate à evasão escolar e apresentar os índices de evasão. O grupo terá quatro meses para a conclusão dos trabalhos" (MEC..., 2013).

Usualmente ouvimos diretores de estabelecimentos de ensino imputarem às condições socioeconômicas dos estudantes e à política as mazelas que ocorrem no processo de escolarização e a fuga dos bancos escolares. Fato que demonstra que a instituição não esta preparada para atender aos grupos sociais excluídos dos serviços e da riqueza da sociedade, já que ao longo da história sua função não é possibilitar a democratização do conhecimento científico e a valorização do saber popular, mas privilegiar e atender ao grupo que detém o poder político e econômico.

$\mathrm{Na}$ verdade, os processos educativos não visam o desenvolvimento de conhecimentos e habilidades voltadas à emancipação, mas para a reprodução das ideias, valores e princípios da burguesia, além de reforçar a disciplina com a finalidade de atender interesses e necessidades do mercado. A criança e o adolescente que não conseguem se 
adaptar à disciplina da escola e não apreender os conteúdos curriculares são consideradas responsáveis por suas dificuldades e problemas.

Portanto, a escola onde se desenvolve os projetos educativos para grupos sociais de trabalhadores: “[...] deve dar-se a fim de habilitá-los técnica, social e ideologicamente para o trabalho. Trata-se de subordinar a função social da educação de forma controlada para responder às demandas do capital" (FRIGOTTO, 2010 p. 28).

$\mathrm{Na}$ entrevista com dois diretores, eles direcionam a responsabilidade pela ausência e não permanência aos próprios estudantes e, em seguida, às famílias:

[...] as crianças não vêm para escola se ela não quiser, porque aqui tem o comer ou é a questão do meio que ele vive eu tenho a impressão que não vem para escola, primeiro porque ela não conta nem com a família, porque aqui na escola não tem atrativo, o único atrativo aqui na escola são as aulas de educação física [...] segundo ela não tem vontade de estudar se ela pode fazer outras coisas ela não vem para escola, terceiro os amigos estão lá na rua, às vezes eles não têm calça para vir na escola, às vezes não têm um tênis [...] (Diretora B).

[...] tem todas as áreas da assistência social então por falta de material, por falta de alimentação, muito pelo contrário os alunos têm alimentação nas escolas têm o material na escola, a não permanência é pelo descompromisso realmente do aluno e muitas vezes da família mesmo [...] (Diretor $D$ ).

No que se refere à família, conforme os diretores entrevistados, os problemas sociais identificados nas escolas estão relacionados ao ambiente familiar dos estudantes, como abandono material e afetivo, violência doméstica, uso abusivo de substâncias psicoativas, negligência e/ou desemprego dos responsáveis. Estas situações repercutiriam no seu comportamento e aprendizado:

[...] são filhos de pais drogados, têm irmãos presidiários, têm alunos que os pais vivem do tráfico de drogas, têm mães alcoólatras, pais alcoólatras [...] então eles vêem assim com um monte de sequelas da vida social que levam no bairro [...] (Diretora B).

[...] o contexto social que ela vive é tão sério e quando ela chega aqui na escola ela fica agressiva, ela fala palavrões, pois é esta a rotina dela, ela agride os outros [...] (Diretora C).

Entendermos e definirmos família na contemporaneidade é tarefa complexa porque encontramos uma diversidade de organização familiar, não cabendo mais a ideia difundida de que a família é constituída por um pai, uma mãe e os filhos. Assim, buscamos em Mioto 
(2010) uma definição para este grupo social que se constrói, se desconstrói e se reconstrói segundo o contexto social, cultural, político e econômico no momento em que se constitui:

Espaço altamente complexo, que se constrói e se reconstrói histórica e cotidianamente por meio das relações e negociações que se estabelecem entre seus membros, entre seus membros e outras esferas da sociedade e entre ela e outras esferas da sociedade, tais como Estado, trabalho e mercado (MIOTO, 2010, p. 3).

A autora ainda destaca que família é o processo no qual se cruza e se estabelece diferentes trajetórias de vida, diferentes e diversas relações de classe, gênero e geração. Desse modo, falar de família é levar em conta que é uma unidade social constituída de múltiplas formas: casal com filhos, casal sem filhos, casal formado por pessoas do mesmo sexo, família chefiada por mulheres, casas onde coabitam mais de um núcleo familiar (MIOTO, 2010).

Entretanto, a direção da escola visualiza essas diferentes formas de organização de família como algo negativo no desempenho dos estudantes. A maioria dos diretores denomina tais arranjos familiares como "família desestruturada":

[...] as nossas crianças são de famílias desestruturadas ou criadas por um parente próximo, uma parte considerável dos nossos alunos são criados por avó, por tio, ou só pela mãe ou só pelo pai [...] (Diretora C).

Para os diretores, a concepção de família estruturada envolve ideias como trabalho, emprego, renda, a presença de um pai e de uma mãe, e o pertencimento a uma religião, fatores importantes para garantir o desenvolvimento social e psicológico da criança e do adolescente.

É uma família que tem moral, pai trabalhador, mãe trabalhadora, o filho obediente aos pais, que eles colocam leis e regras, que tem religiosidade, tem uma religião, não importa, mas que se crê em alguma coisa [...], (Diretora B).

[...] um pai, uma mãe, pelo menos um deles empregados e responsável pela criança, e quando você tem um pai e uma mãe presente, um dos dois trabalhando, sabe quando o filho vem na escola [...] (Diretora C).

De acordo com Perez (2009), as escolas, de modo geral, procuram incentivar a família a frequentar o espaço escolar, principalmente por meio de reuniões ou festas que 
envolvem as crianças, os adolescentes e os seus responsáveis (dia das mães, dia dos pais, dia das crianças, festa junina). Mas, as oportunidades de participar do processo educacional dos filhos são poucas, pois o convite à participação se dá geralmente quando o estudante tem problemas disciplinares e de aprendizagem; e seria a família, no parecer dos professores, responsável para solucionar esta questão:

Olha, hoje ainda está muito distante [...] quando tem assinatura de boletim, quem precisa realmente vir não vem. A gente tem que convocar, intimar o aluno, dizer que não vai entrar se o pai não vir [...] (Diretor $A$ )

O nosso maior problema social realmente é o comprometimento da família com o acompanhamento do aluno na escola, porque têm famílias que não fazem esse acompanhamento como deveria, deixa toda essa responsabilidade para a escola [...] (Diretor D).

A relação família e escola é permeada pela ideia de que há desinteresse dos responsáveis por acompanhar a vida escolar de seus filhos. Os diretores informaram que algumas vezes os pais não sabem que os filhos estão faltando às aulas, porque eles se "perdem" no caminho de casa para a escola:

[...] muitas vezes ele sai de casa e não chega à escola [...] sai de casa bonitinho de uniforme e não chega na escola, por pura irresponsabilidade e a família não está sabendo disso [...] tem alguns casos que o pai e a mãe trabalham o dia todo e não conseguem ter um controle realmente efetivo se o aluno está chegando na escola [...] (Diretor D).

[...] A gente quando comunica à família que o aluno está faltando, o pai fala "mas ele está vindo", e dai o que a gente faz, a gente convoca a família, daí no outro dia ela aparece, depois na outra semana falta de novo, porque tem criança que no caminho da casa até a escola, ele não chega a escola [...] (Diretora C).

Abordamos a questão socioeconômica e política como uma entre tantas outras causas para o abandono dos bancos escolares. Porém, não devemos negligenciar as práticas pedagógicas que podem contribuir para a repetência e a evasão, como aulas monótonas que não proporcionam desafios; conteúdos distantes da realidade em que vive o estudante; pouco incentivo à pesquisa - e à curiosidade - não estimulando o estudante a buscar respostas além dos muros escolares; enfim, a falta de atratividade das aulas e a consequente desmotivação do aluno (RUARO, 2012, p. 7). 
Não pretendemos reforçar a ideia de que o responsavel pela não permanência do educando na escola encontra-se em pessoas ou em categorias profissionais, haja vista que atualmente estamos passando por um novo processo no que se refere a encontrar responsáveis pela evasão escolar. Perez (2009) destaca que em determinado período a criança foi considerada culpada por sua condição, ou porque não gostava de estudar, ou era desatenta, ou era preguiçosa. Atualmente, o foco volta-se para dentro da escola, particularmente para o docente, que tem sido considerado o culpado por não ser dinâmico e criativo em suas aulas, por ser desinteressado pela melhoria da educação escolar.

Essa visão simplista e distorcida da educação escolarizada não considera a complexidade dos estabelecimentos de ensino como instituição social e política, destarte as condições de trabalhos dos profissionais da educação não serem levadas em consideração pelos gestores, como salários extremamente baixos, aquém das necessidades dos professores, jornada de trabalho extenuante, escolas sem equipamentos mínimos necessários para o bom funcionamento, salas de aula lotadas (PATTO apud PEREZ, 2009).

Mais uma vez destacamos que este não é um problema apenas do município de Rolândia. Basta lermos a reportagem de um periódico de circulação nacional:

Os resultados do Programa Internacional de Avaliação de Estudantes (Pisa, na sigla em inglês), divulgados no final de 2013, mostraram que os países com melhor desempenho na educação são aqueles que fazem a carreira docente atrativa aos mais talentosos jovens que saem do ensino médio. Não é o nosso caso (VIEIRA, 2014).

Desde os anos de 1930, o fracasso escolar decorrente da reprovação ou da evasão é acompanhado do discurso oficial (de ministros, secretários estaduais e municipais) que defende a melhoria na educação escolarizada, com a compra de mais livros, contratação de professores, distribuição de merenda, transporte escolar eficiente. Porém, o que constatamos é que não são concretizadas minimamente estas propagadas melhorias, como podemos, mais uma vez, ler em uma matéria jornalística:

No mês da volta às aulas, o caminho é de obstáculos para boa parte dos 4,9 milhões de estudantes da rede pública brasileira que dependem de transporte escolar. Veículos sem manutenção, ônibus que quebram e viagens longas que cobrem mais de uma região desestimulam os estudantes. Entre os alunos, a viagem é acompanhada por uma incerteza: a frequência nas aulas. A precariedade do serviço é apontada pela União Nacional dos Dirigentes de 
Educação (Undime) como fator determinante para a evasão escolar (REMÍGIO; MARTIN, 2011).

A ideia disseminada por diretores, gestores e reforçada pela mídia é a de que os problemas ocorrem em virtude de situações pontuais que o poder público (municipal ou estadual) ou famílias vivem - desemprego, dependência química, violência doméstica. Portanto, encontrar possíveis responsáveis evita o questionamento de uma educação que não considera as necessidades de docentes, discentes, família e comunidade. Resolvidos estes problemas, a evasão escolar estaria solucionada!

\section{O Serviço Social e as possibilidades de atuação nas escolas}

A permanência na escola é determinada pela Constituição Federal, a Lei de Diretrizes e Base da Educação Nacional e o Estatuto da Criança e do Adolescente. No entanto, não é o que temos observado cotidianamente nas unidades de ensino, não obstante os diretores relatarem que quando constatam um problema com a criança ou o adolescente - violência doméstica, uso de substâncias ilícitas, negligência dos responsáveis - relatam ao Conselho Tutelar para tomar as medidas cabíveis. E o Serviço Social, como poderia contribuir para dirimir essa situação que muitas vezes levam ao abandono escolar?

Piana (2009) afirma que o trabalho do Serviço Social no campo da educação ainda é pouco reconhecido pelos profissionais que atuam em unidades de ensino. Afinal, usualmente há a percepção de que a escola é o espaço ocupado por profissionais diretamente envolvidos com o processo ensino-aprendizagem. Portanto, de onde vem a demanda para ter um profissional da área do Serviço Social em unidades escolares?

Os diretores das escolas de Rolândia que entrevistamos afirmaram que somente o pedagogo não consegue responder às questões que ultrapassam o espaço educacional, sendo necessária a contribuição de outros profissionais, como assistentes sociais e psicólogos, para atuarem em conjunto a professores e pedagogos. Segundo seus relatos, tais profissionais atuariam nos problemas que os estudantes trazem de casa para o interior da unidade escolar, desenvolveria atividades junto às famílias e realizaria encaminhamentos para a rede de serviços, ressaltando que seria importante o trabalho em conjunto com um psicólogo, outro profissional que poderia contribuir para a permanência do estudante: 
Olha, eu acredito que se tivesse um assistente social a sala de aula estaria sempre lotada mesmo, porque todos os alunos trazem os problemas de casa, acaba influenciando o rendimento escolar [...] um psicólogo e um assistente social iria ajudar nesta parte [...] (Diretor $A$ )

[...] Se tivesse uma assistente social seria muito mais fácil os encaminhamentos dos alunos com problemas [...] (Diretora $B$ )

[...] a equipe pedagógica precisa de um assistente social, porque a atuação é mais direcionada tem um foco na questão social e nós enquanto pedagogo, professores não tem como chegar, nosso foco é educacional então não podemos abrir muito o leque porque se não, não dá conta [...] (Diretora C).

Foi obervado nas escolas vários problemas de ordem social - saúde precária, negligência material e afetiva, violência doméstica, uso de substâncias químicas ilícitas -e é o pedagogo atualmente o responsável por lidar com estas situações. Porém, eles não conseguem dar conta de tais questões, conforme relato de um diretor: "[...] seria primordial o trabalho do assistente social [...] facilitaria muito, não ficaria só a cargo do pedagogo, porque na maioria das vezes o pedagogo que tem que fazer o trabalho do assistente social [...]" (Diretor D).

Mas, diante das falas desses gestores surge a preocupação de que para estes o profissional do Serviço Social contratado para atuar nas unidades de ensino viria para resolver os problemas de indisciplina, de repetência, de evasão, deixando os professores mais tranquilos para exercerem suas atividades, ou seja, o/a assistente social viria para salvar os docentes dos problemas extraclasses que interferem nas atividades pedagógicas. Mas, como deve o/a assistente social exercer sua prática: atender às demandas do docente, do estudante ou da comunidade?

O profissional da área do Serviço Social em sua formação profissional deve fazer o movimento da singularidade, da particularidade e da universalidade (GONÇALVES, 2009), possibilitando o conhecimento crítico da sociedade com uma visão da totalidade social, e assim compreender o contexto econômico, social e cultural dos estudantes e os motivos que os impedem de permanecer nas escolas.

O Código de Ética Profissional em seus princípios fundamentais destaca que nossa atuação deve pautar-se pela defesa dos direitos humanos, sociais e políticos da classe trabalhadora. Desta forma, devemos garantir, no caso da Política de Educação, os direitos 
do educando, sua família e mesmo os docentes, porque todos estão envolvidos no processo que envolve o ensino e a aprendizagem.

Afinal, para garantir um projeto educativo emancipatório é necessário que o conhecimento seja instrumento para os estudantes fazerem descobertas e realizarem experiências em interação com a realidade na qual estão imersos. Nesta perspectiva, o/a assistente social deve atuar no sentido de possibilitar que a educação escolar seja impulsionada por relações de respeito e reconhecimento entre os sujeitos envolvidos na prática pedagógica, isto é, reconhecimento das diferenças sociais, culturais, étnicas, religiosas, de gênero.

A lógica do mercado determina as ações do Estado, que vem reduzindo gastos com as políticas sociais e relegando para a sociedade civil e o terceiro setor a tarefa de atender às necessidades da população, entre elas a educação. Assim, a função da educação escolarizada é preparar e qualificar mão de obra para atender às necessidades do mercado, consolidando e reproduzindo, além disso, um pensamento homogênio que apreende a sociedade desigual como natural e inevitável e não prepara os educandos para serem sujeitos de sua própria história. Nas palavras de Mészáros (2008, p. 45): “Uma das funções principais da educação formal nas nossas sociedades é produzir tanta conformidade ou 'consenso' quanto for capaz, a partir de dentro e por meio dos seus próprios limites institucionalizados e legalmente sancionados".

Seguindo esse raciocino, o profissional do Serviço Social em sua atuação deve considerar a importância de um trabalho interdisciplinar, tendo em vista que para garantir a permanência do estudante na escola é necessário o entendimento de que os problemas e situações vivenciadas no interior da escola vão além das atividades pedagógicas.

Conforme Almeida (2011, p. 25):

Pensar a inserção dos assistentes sociais na área da educação coloca o desafio de compreender e acompanhar teórica e politicamente como que as requisições postas a este profissional estão articuladas às tendências contraditórias da política de educação de ampliação das formas de acesso e de permanência na educação escolarizada, diante de um cenário em que a realidade encontra-se cada vez mais imbricada com a dinâmica do capital.

Assim sendo, o Serviço Social poderá atuar no campo educacional executando programas e projetos que subsidiem as políticas setoriais - saúde, habitação, assistência 
social - voltadas às necessidades de estudantes, famílias e comunidade; além de desenvolver atividades de interação grupal entre os sujeitos envolvidos no processo educativo, fomentando uma educação escolarizada que garanta a permanência do aluno na escola.

Segundo Almeida (2011, p. 57), as reflexões sobre o trabalho do assistente social nas escolas

[...] devem, portanto, articular o acúmulo teórico-crítico do Serviço Social em relação ao campo das políticas sociais e dos direitos sociais, das competências previstas na Lei que regulamenta a profissão com as particularidades da política educacional.

O/A assistente social, atuando em uma equipe interdisciplinar - pedagogos, professores, psicólogos -, poderá contribuir na permanência e no combate à evasão escolar por meio da execução de atendimentos individuais (com os estudantes e/ou com seus responsáveis), reunião com a comunidade que gira em torno da escola, criando ou fortalecendo os conselhos Escola-Comunidade, as Associações de Pais e Mestres, reunião com os profissionais da educação da própria escola e das escolas próximas, com vistas a discutir os problemas comuns; visitas domiciliares aos estudantes e suas famílias, possibilitando conhecer sua realidade socioeconômica e cultural; contato e articulação com a rede de serviços do território, com vistas a encaminhamentos e discussões de situações que aparecem cotidianamente no interior das escolas.

Devemos destacar também a possibilidade de colaborar na elaboração de programas e projetos que tenham por finalidade o debate e a prevenção à violência intra e extramuros escolares, o consumo de substâncias químicas lícitas e ilícitas, e às questões relacionadas à sexualidade e à saúde do educando.

Cabe ao profissional do Serviço Social não perder de vista que os sujeitos envolvidos nas práticas educativas - crianças, adolescentes, docentes, família e mesmo a comunidade -, cada um com suas peculiaridades, especificidades e perspectivas, ora em comum, ora contraditória, têm interesses e objetivos próprios quando entram na escola, e que deveriam estar a serviço das necessidades do educando. Desta forma, o/a assistente social terá de lidar e contornar estas questões intra e extra muro escolar. 


\section{Algumas considerações}

Os problemas e conflitos que eclodem no interior da escola são tratados como um problema individual que deve ser resolvido caso a caso. Nesta perspectiva, a permanência, ou não, na escola, depende apenas da vontade do educando. Podemos afirmar que a não permanência na escola e a consequente evasão demonstra o fato de a criança e o adolescente estarem regularmente matriculados, mas não significa que estejam frequentando as aulas.

Enfrentar esta questão exige a construção de uma prática educativa que reconheça o saber popular, leve os educandos a aprender a interrogar e a questionar sua realidade, contribuindo para a constituição de indivíduos que reconheçam e valorizem sua história e de sua comunidade.

Convictas da importância de buscarmos uma educação que respeite as diferenças culturais e históricas dos sujeitos, acreditamos que o profissional do Serviço Social inserido em uma unidade escolar se engajaria na proposta de uma educação emancipadora, atuando em uma equipe interdisciplinar para contribuir e garantir a permanência do estudante na escola, por meio de atividades individuais e coletivas, elaboração de projetos que envolveria a comunidade escolar e mesmo o território onde encontra-se a escola, com vistas a encontrar alternativas para possibilitar esta permanência.

Enfim, um profissional mais próximo da realidade dos sujeitos envolvidos no processo educativo, e que com o seu conhecimento contribua para encontrar alternativas para superar os limites impostos por interesses dos grupos dominantes e tornar a educação uma prática social inovadora, com relações baseadas no respeito às diversidades.

O leitor poderá argumentar que isto é uma utopia. Mas, o que seríamos de nós se não sonhássemos!

\section{Referências}

ALMEIDA, N. L. T. de. Apontamentos sobre a política de educação no Brasil hoje e a inserção dos assistentes sociais hoje. In: CAMPOS, E. B. et al. Subsídios para o debate sobre o serviço social na educação. Conselho Federal de Serviço Social - Grupo de Trabalho de Educação. Brasília, 2011. 
BRASIL. Constituição da República Federativa do Brasil de 1988. Disponível em: <http://www.planalto.gov.br/ccivil_03/constituicao/constituicao.htm>. Acesso em: 4 abr. 2012.

BRASIL. Lei no 8.069, de 13 de julho de 1990. Dispõe sobre o Estatuto da Criança e do Adolescente e dá outras providências. Disponível em:

<http://www.planalto.gov.br/ccivil_03/leis/L8069.htm>. Acesso em: 5 maio 2012.

BRASIL. Lei no 9.394, de 20 de dezembro de 1996. Estabelece as diretrizes e bases da educação nacional. Disponível em:

<http://www.planalto.gov.br/ccivil_03/leis/L9394.htm>. Acesso em: 24 maio 2012.

IBGE. Paraná: Rolândia. Disponível em: <http://cidades.ibge.gov.br/xtras/ perfil.php?codmun=412240>. Acesso em: 10 jan. 2014.

IBGE. Censo demográfico: resultados gerais da amostra. 2010. Disponível em: <http://censo2010.ibge.gov.br/resultados>. Acesso em: 10 maio 2012.

CONSELHO FEDERAL DE SERVIÇO SOCIAL - CFESS. Subsídios para o debate sobre o serviço social na educação. Brasília: CFESS, 2011.

FRIGOTTO, G. Educação e a crise do capitalismo real. 6 ed. São Paulo: Cortez, 2010.

GONÇALVES, A. B. A prática cotidiana do assistente social na escola privada. 2009. Dissertação (Mestrado em Serviço Social) - Universidade Estadual de Londrina, Londrina, Paraná.

HADDAD, C. R.; FRANCO, A. F.; SILVA, D. V. Os motivos da evasão escolar: uma análise do Programa FICA. In: CONGRESSO NACIONAL DE EDUCAÇÃO, 10., SEMINÁRIO

INTERNACIONAL DE REPRESENTAÇÕES SOCIAIS, SUBJETIVIDADE E EDUCAÇÃO, SIRSSE, 2., 2011, Curitiba. Anais... Curitiba, 2011. Disponível em:

<http://educere.bruc.com.br/CD2011/pdf/4204_2327.pdf>. Acesso em: 10 ago. 2012.

MÉSZÁROS, E. A educação para além do capital. 2. ed. São Paulo: Boitempo, 2008.

MIOTO, R. C. T. Família e assistência social: subsídios para o debate do trabalho dos assistentes sociais. In: ALENCAR, M. M. T.; DUARTE, M. J. O. Familia \& famílias: práticas sociais e conversações contemporâneas. Rio de Janeiro: Lúmen Júris, 2010. p. 3-14.

MEC cria grupo para combater a evasão escolar. G1 Educação, Rio de Janeiro, 25 nov. 2013. Disponível em: <http://oglobo.globo.com/sociedade/educacao/mec-cria-grupopara-combater-evasao-escolar-10872241>. Acesso em: jan. 2014.

PEREZ, M. C. A. Família e escola na contemporaneidade: fenômeno social. Revista lberoAmericana de Estudos em Educação. São Paulo, v. 4, n. 3, 2009. Disponível em: <http://seer.fclar.unesp.br/iberoamericana/article/view/2763/2499> Acesso em: 10 ago. 2012. 
PIANA, M. C. A construção do perfil do assistente social no cenário educacional. São Paulo: Cultura Acadêmica, 2009. Disponível em:

<http://pt.scribd.com/doc/28983946/Construcao-Do-Perfil-Do-Assistente-Social>. Acesso em: 12 jul.2012.

PIANA, M. C.; CANÔAS, J. W. Educação: direito social a ser efetivado. Serviço Social e Realidade, Franca, v. 16, n. 1, p. 201-218, 2007.

QUINTAL, T. M. M. Educação para o pensar e educação emancipatória. 2010. Disponível em: <http://www.uninove.br/PDFs/Mestrados/Educa\%C3\%A7\%C3\%A3o/eventos/ PC\%2010.pdf>. Acesso em: 15 maio 2014.

REMÍGIO, M.; MARTIN, I. Transporte escolar ruim compromete segurança e aumenta evasão de alunos. G1 Política, Rio de Janeiro, 4 nov. 2011. Disponível em:

<http://oglobo.globo.com/politica/transporte-escolar-ruim-compromete-segurancaaumenta-evasao-de-alunos-2817357\#ixzz2U1PqAw6a>. Acesso em: 20 abr. 2013.

ROLÂNDIA. Prefeitura municipal. História de Rolândia. Disponível em:

<http://www.rolandia.pr.gov.br/>. Acesso em: 29 out. 2012.

RUARO, L. M. Do fracasso da didática à evasão escolar? Ou da evasão ao fracasso escolar. Disponível em: <http://www.portalanpedsul.com.br/>. Acesso em: 12 set. 2012.

SANTIAGO, M. Pedagogia crítica e educação emancipatória na escola pública: um diálogo entre Paulo Freire e Boaventura Santos. In: SEMINARIO DE PESQUISA EM EDUCAÇÃO DA REGIÃO SUL, 9., 2012, Caxias do Sul. Anais... Caxias do Sul, 2012. Disponível em: <http://www.ucs.br/etc/conferencias/index.php/anpedsul/9anpedsul/paper/viewFile/22 5/217>. Acesso em: 15 out. 2014.

VIEIRA, L. Salários de professores melhoram, mas magistério atrai menos jovens. G1 Educação, Rio de Janeiro, 9 set. 2014. Disponível em: <http://oglobo.globo.com/ sociedade/educacao/salarios-de-professores-melhoram-mas-magisterio-atrai-menosjovens-11210310>. Acesso em: 10 jan. 2014. 